\title{
Shining a Light also Casts a Shadow: Neuroimaging Incidental Findings in Neuromarketing Research
}

\author{
Owen M. Bradfield $\mathbb{D}$
}

Received: 14 November 2020 / Accepted: 22 March 2021 / Published online: 12 April 2021

(C) The Author(s) 2021

\begin{abstract}
Rapid growth in structural and functional brain research has led to increasing ethical discussion of what to do about incidental findings within the brains of healthy neuroimaging research participants that have potential health importance, but which are beyond the original aims of the study. This dilemma has been widely debated with respect to general neuroimaging research but has attracted little attention in the context of neuromarketing studies. In this paper, I argue that neuromarketing researchers owe participants the same ethical obligations as other neuroimaging researchers. The financial resources available to neuromarketing firms and the social value of neuromarketing studies should command greater attention to the elucidation and management of incidental findings. However, this needs to be balanced against finite resources available within most public health systems.
\end{abstract}

Keywords Incidental findings · Neuroethics ·

Neuromarketing $\cdot$ Research ethics

\section{Introduction}

Our quest to understand the human brain has generated growing interest in structural and functional brain

O. M. Bradfield ( $\square)$

Law \& Public Health Unit, Centre for Health Policy, Melbourne School of Population \& Global Health, University of Melbourne, Melbourne, Australia

e-mail: o.bradfield@student.unimelb.edu.au research [1]. However, neuroimaging research frequently detects "structural findings within the brains of healthy neuroimaging research participants that have potential health importance, but which are beyond the original aims of the study" [2]. These "neuroimaging research incidental findings" ("NRIFs") can occur in up to one in 37 brain scans, although rates are lower in younger healthy participants [3]. Knowing what to do about NRIFs has been the subject of much ethical discussion [4]. With large neuroimaging cohort studies involving hundreds of thousands of brain scans currently underway in the UK, [5] US, [6] France, [7] Canada, [8] Germany [9] and the Netherlands, [10] increasing numbers of NRIFs will be detected. Correctly identifying and characterising clinically significant NRIFs can be challenging [11]. NRIFs can range from benign incidental anatomical variations to life-threatening vascular or neoplastic lesions. Detection rates may be influenced by imaging, reader, and participant factors. Disclosure of significant NRIFs to participants may facilitate timely treatment that reduces morbidity and mortality, while disclosure of benign or false-positive NRIFs may lead to unnecessary alarm or anxiety for participants [12].

"Neuromarketing" describes neuroimaging research that examines the human brain's response to marketing stimuli [13]. Like all neuroimaging, neuromarketing can also uncover NRIFs. While neuromarketing is typically conducted in younger healthy adults in whom the incidence of NRIFs is lower, the ethical obligations of neuromarketing researchers to seek or disclose NRIFs to participants has attracted little attention. In this paper, 
I will argue that the financial wealth of many private neuromarketing firms creates moral obligations to design research protocols that facilitate the detection and disclosure of NRIFs. The self-interest and absence of public good in some private neuromarketing produces a greater moral obligation to protect participants from foreseeable harms. This paper will focus on the obligations of disclosure owed to adult research participants. The issues in children are more complex [14] and require detailed consideration beyond the scope of this paper.

\section{Duty of Easy Rescue}

Research participants place their health and trust in researchers when participating in research. They rely on researchers to minimise harm and to maintain confidentiality. [15] Researchers are more than mere scientists and owe moral obligations to participants that can be grounded in the "rescue principle":

\section{...if you are presented with a situation in which you can prevent something very bad from happen- ing, or alleviate someone's dire plight, by making only a slight (or even moderate) sacrifice, then it would be wrong not to do so.[16]}

Peter Singer conceives this principle using his shallow pond example:

...if I am walking past a shallow pond and see a child drowning in it, I ought to wade in and pull the child out. This will mean getting my clothes muddy, but this is insignificant, while the death of the child would presumably be a very bad thing. [17]

This moral duty is shaped by the urgency of the situation, the consequences of inaction and the exertion required by the potential rescuer to prevent harm. While many neuroethicists agree that researchers ought to disclose clinically significant NRIFs to participants, there is less consensus about NRIFs that are not serious, urgent or easily treatable [18]. In these cases, it is unclear whether participants are being rescued and, if they are, whether the rescue can be easily achieved. Thus, the principle of reciprocity could be employed to strengthen arguments for disclosure: participants should receive information about any NRIF that they can reasonably understand [19] in recognition of their contribution to the research. [20] Even if NRIFs are rare, they are not unexpected, and researchers should anticipate and plan for NRIFs by explaining their likelihood, significance and management with participants when informed consent is obtained.[21] In particular, the implications of detecting different types of NRIFs should be discussed as well as whether (and, if so, which) NRIFs will be communicated to participants and by whom [22].

Although much has been written about the ethics of NRIFs, [23] the specific obligations of neuromarketing researchers to seek or disclose NRIFs to participants has attracted little attention. Neuromarketing research remains poorly regulated. Few research protocols or results are subject to public or scientific scrutiny [24]. The focus on profits, rather than knowledge, may undermine the interests of participants and the integrity of researchers. Using neuroimaging to sell products has been described as a "soft attack on autonomy", [25] while the transfer and harvest of private thought to commercial companies for revenue may be a soft attack on privacy.

Despite these criticisms, Wertheimer [26] argues that private research, such as that typically conducted by neuromarketing firms, is merely a transaction between researcher and participant. Therefore, obligations to disclose NRIFs can be mutually negotiated and competent adults could consent to foregoing knowledge of NRIFs in exchange for proportionate financial reward or compensation. However, it is difficult to see how payment of participants by private neuromarketing firms could ever fully restore asymmetries in knowledge because private research is not a purely binary transaction. For example, a chemical company responsible for poisoning a water supply owes moral obligations to communities harmed by the pollution. These externalities ground the moral claims of parties outside a transaction [27]. The same applies to NRIFs.

Neuromarketing researchers have access to information not available to participants that can have downstream implications for participants, their families and society. If private neuromarketing researchers detect but do not disclose an NRIF, the participant loses the opportunity to make an autonomous decision about how to manage that finding. This has implications for the health of the participant and the allocation of scarce health resources because delayed treatment may be more invasive, more costly and less effective than earlier intervention. In addition, non-disclosure may have wider societal implications. For instance, non-disclosure of an 
NRIF with potential to cause future seizures could significantly impact on the wellbeing of passengers and other road users if the participant is a bus-driver and has a seizure while driving a bus because they were unaware of the presence of the NRIF. Equally, at-risk family members should also be considered in the discussion of NRIFs that suggest a heritable condition [28]. Family members may want to know if they are at risk of a lifelimiting medical condition, such as a cerebral aneurysm.

Allowing neuromarketing firms to contract out of disclosure of NRIFs by compensating participants does not create a fair or equitable transaction. In fact, empirical evidence shows that up to $95 \%$ of participants want to receive information about NRIFs. [29] In one study, $79 \%$ believed that the advantages of feedback outweighed the disadvantages, regardless of curability [30]. In another study, $90 \%$ of participants assumed that their neuroimaging scans would be evaluated for NRIFs and that the absence of feedback from researchers implied that no NRIFs were detected [31]. When neuromarketing researchers involve participants in their pursuit of profit, they assume a set of moral responsibilities that extends to the management and disclosure of NRIFs. Hence, private neuromarketing firms owe the same core moral obligations towards research participants as other neuroimaging researchers. In fact, the amount of funding and the absence of public or scientific scrutiny may even shift these fundamental duties further in favour of disclosure.

\section{Resource Allocation}

One argument against seeking and disclosing NRIFs is that the cost of doing so impedes beneficial research in the public interest:

\section{In the current climate, half as much research [would] get done, and that has... a much greater impact on society and the health of society than the very, very low incidence of incidental findings which are actually correct and an even lower incidence where there is something you could have done [32].}

Scarce research funding must be efficiently and fairly allocated so as to maximise and expedite valid research, while protecting participants from unnecessary risk. Most neuroimaging research is conducted using scanners that are not of diagnostic quality. Although this reduces the time and cost of obtaining scans, it hinders the detection and interpretation of NRIFs [33]. Routinely employing diagnostic quality scanners in neuroimaging research adds six minutes [34] and US\$23 [35] to the cost of each scan. This could delay the acquisition and dissemination of vital results and divert funding away from primary research questions. More lives could be impacted by delayed results than by not detecting or disclosing NRIFs.

Likewise, most public neuroimaging research lacks sufficient funding to employ dedicated neuroradiologists to review neuroimaging scans. Consequently, they are often reviewed by researchers without medical training [36]. In one study, only $38 \%$ of neuroimaging research projects used a radiologist [37]. Those that did, limited their involvement to reviewing scans flagged as potentially abnormal by non-medically trained researchers. Unless neuroradiologists review all scans, NRIFs may be missed. In addition, nonmedically trained researchers may be unable to discuss radiological findings with participants. However, employing neuroradiologists could impact research budgets and research outcomes by reducing the number of participants recruited and scanned, ultimately reducing the statistical power of the study and the validity of results. In the case of urgent research or research conducted on a limited budget, this is problematic.

Despite these legitimate arguments, private neuromarketing firms are rarely scarcely resourced. Indeed, they often operate large budgets to commission neuromarketing research in pursuit of greater profits. Mandating the use of diagnostic quality scanners or neuroradiologists would be less burdensome for private neuromarketing companies than for publicly-funded neuroimaging researchers and would doubtless enhance the wellbeing of participants through earlier and better detection of NRIFs. Using Singer's concept of the duty of easy rescue as an ethical basis for requiring researchers to adopt these measures to seek and detect NRIFs, we could argue that having access to a bigger budget for research that is not urgent creates an opportunity for easier rescue. Therefore, it might be argued that neuromarketing firms owe participants a greater moral obligation to identify and seek NRIFs. Again, using the shallow pond example, suppose that a child is drowning in the centre of a shallow pond and there are two bystanders: one is short in stature and cannot swim, the other is a tall and proficient swimmer. The tall 
proficient swimmer owes the child a greater moral obligation to assist because the personal risk and effort required is less. By analogy, the private neuromarketing firm is tall and pecunious and can more easily afford to seek and detect NRIFs.

However, resource allocation is a double-edged sword. Access to magnetic resonance imaging (MRI) scanners [38] and radiologists [39] is limited in many countries. By requiring neuromarketing researchers to generate diagnostic quality scans that are interpreted only by neuroradiologists, competition for access to these limited resources could increase. While private neuromarketing firms could purchase their own MRI scanners, they cannot train more neuroradiologists. By luring neuroradiologists away from public hospitals with the prospect of generous salaries, private neuromarketing firms may create workforce shortages and leave public hospitals with even less capacity for neuroradiological expertise. Therefore, it is critical to ensure that, in our haste to protect the welfare of participants by imposing moral obligations on neuromarketing researchers, we do not create inequity of access to crucial healthcare that is ultimately detrimental to the public interest [40]. To help us decide how limited resources should be properly allocated, I turn my attention to the social value of neuromarketing research when competing for scarce resources.

\section{Social Value of Neuromarketing Research}

It is ethically impermissible to engage in research that exposes participants to significant risks, unless those risks are justified by the importance of the knowledge that the research will uncover. As outlined in the Nuremberg Code, "the experiment should ... yield fruitful results for the good of society" [41]. Likewise, the Belmont Report requires that potential harms to participants be balanced against the "anticipated benefit to society in the form of knowledge to be gained from the research"[42].

In recent years, risk-benefit evaluations in research have moved away from the view that informed consent alone allows researchers to expose participants to risk. Instead, the scientific or social value of the research should also guide decisions [43]. Risks to participants should be acceptable and proportionate to the potential benefits for participants and/or society. Studies should be designed to expose participants to the minimum risk necessary to generate clear and testable hypotheses, reliable information and valid results. Greater social value is required to justify greater risks to participants. On the contrary, research of limited scientific or social value should expose participants to no more than negligible risk.

Neuromarketing research can contribute to our understanding of the human brain in health and disease and can contribute to socially useful outcomes. For example, neuromarketing has been used to improve smoking cessation campaigns [44]. However, when neuromarketing research is conducted by private companies that do not publish their methods or results, the social value of the research is diminished. Furthermore, methodologically flawed neuromarketing research aimed at manipulating people for purely financial gain may erode public confidence in neuroimaging research more generally. For example, an opinion-editorial published in the New York Times purportedly demonstrating that young people "loved" their iPhone [45] was widely criticised as drawing hefty conclusions from limited functional MRI data [46]. Society should be reluctant to allow private neuromarketing firms to conduct unscientific profit-generating research when it exposes participants to unnecessary risks, even if those risks are purely informational. Rigorous standards for detecting and disclosing NRIFs should ensure that participants in neuromarketing research are no worse off than before they agree to participate.

In making decisions about priority of access to diagnostic neuroimaging and neuroradiologists, we must weigh the social value of neuromarketing research against the social value of clinical care or other research endeavours. Hence, determination of the social value of neuromarketing research must guide decisions about the appropriate steps to take in detecting and disclosing NRIFs and whether those steps are justified when balanced against competing demands on limited healthcare resources. Fundamentally, if risks to participants cannot be minimised in a way that does not reduce access to vital neuroimaging expertise, then it would be morally impermissible to allow the research to proceed at all. In short, we must ensure that enhancing participant welfare, by requiring NRIFs be sought and disclosed, does not diminish overall societal welfare.

\section{Conclusion}

If we accept that neuroimaging researchers owe research participants a moral obligation to seek and disclose NRIFs, then private neuromarketing firms owe 
participants the same core ethical obligations. In fact, the source and availability of funding, the absence of scientific scrutiny and the limited social value of the research may all shift these fundamental duties in favour of disclosure. Many private neuromarketing firms generate significant profits and can easily rescue participants from foreseeable informational risks by employing diagnostic quality scanners and neuroradiologists. This will reduce the likelihood of missing or delaying detection of NRIFs and allow the clinical significance of NRIFs to be more fully characterised. Most importantly, research participants themselves tell us that this is what they want. However, we must ensure that neuromarketing firms are not permitted to purchase scarce public resources to meet these requirements at the expense of public hospitals. Requiring neuromarketing researchers to use diagnostic quality scanners and neuroradiologists to interpret scans puts private marketing firms in competition with health care services for access to limited expertise. While this may directly benefit participants, it may be detrimental to the overall welfare of society if finite resources are diverted away from other essential clinical or research applications.

This paper demonstrates, using the neuromarketing example, that resource allocation and social value should play a greater role in calculating the moral obligations of researchers to seek and disclose NRIFs. Currently, variation in policies and practice for the detection, storage, management and communication of NRIFs exists. [47] Some researchers actively seek NRIFs and offer participants copies of scans, while others have an absolute "no feedback" policy. Clearly, the appropriate moral response needs to be nuanced and standardised ethical guidance for handling NRIFs in neuromarketing research is urgently required. Fundamentally, a paradigm shift is needed in which NRIFs are recognised as integral to, not separate from, the primary intentions of neuroimaging research.

Acknowledgments The author would like to acknowledge the helpful and insightful comments of Prof Dominic Wilkinson, the University of Oxford.

Availability of Data and Material Not applicable.

Code Availability Not applicable.

Authors' Contributions Sole authorship

Funding The author was supported by a Melbourne Research Scholarship and is also a recipient of a 2020 Fulbright Future Scholarship.
Declarations

Conflicts of interest/Competing interests None

Open Access This article is licensed under a Creative Commons Attribution 4.0 International License, which permits use, sharing, adaptation, distribution and reproduction in any medium or format, as long as you give appropriate credit to the original author(s) and the source, provide a link to the Creative Commons licence, and indicate if changes were made. The images or other third party material in this article are included in the article's Creative Commons licence, unless indicated otherwise in a credit line to the material. If material is not included in the article's Creative Commons licence and your intended use is not permitted by statutory regulation or exceeds the permitted use, you will need to obtain permission directly from the copyright holder. To view a copy of this licence, visit http://creativecommons.org/licenses/by/4.0/.

\section{References}

1. Purves, D., D. Fitzpatrick, G.J. Augustine, and L.C. Katz. 2008. Neuroscience. 4th ed. Sinauer: Sunderland, MA.

2. Wolf, S.M., F.P. Lawrenz, C.A. Nelson, J.P. Kahn, M.K. Cho, E.W. Clayton, J.G. Fletcher, M.K. Georgieff, D. Hammerschmidt, K. Hudson, and J. Illes. 2008. Managing incidental findings in human subjects research: analysis and recommendations. The Journal of Law, Medicine \& Ethics 36 (2): 219-248.

3. Morris, Z., W.N. Whiteley, W.T. Longstreth, F. Weber, Y.C. Lee, Y. Tsushima, H. Alphs, S.C. Ladd, C. Warlow, J.M. Wardlaw, and R.A.S. Salman. 2009. Incidental findings on brain magnetic resonance imaging: systematic review and meta-analysis. BMJ 339.

4. Illes J, Kirschen MP, Edwards E, Stanford LR, Bandettini P, Cho MK, Ford PJ, Glover GH, Kulynych J, Macklin R, Michael DB, 2006. Incidental Findings in Brain Imaging Research: What should happen when a researcher sees a potential health problem in a brain scan from a research subject? Science, 311(5762): p.783.

5. Gibson, L.M., T.J. Littlejohns, L. Adamska, S. Garratt, N. Doherty, J.M. Wardlaw, G. Maskell, M. Parker, R. Brownsword, P.M. Matthews, and R. Collins. 2017. Impact of detecting potentially serious incidental findings during multi-modal imaging. Wellcome open research 2.

6. Insel, T.R., S.C. Landis, and F.S. Collins. 2013. The NIH brain initiative. Science 340 (6133): 687-688.

7. Stephan, B.C., C. Tzourio, S. Auriacombe, H. Amieva, C. Dufouil, A. Alpérovitch, and T. Kurth. 2015. Usefulness of data from magnetic resonance imaging to improve prediction of dementia: population-based cohort study. BMJ: 350.

8. Smith, E.E., M. O'Donnell, G. Dagenais, S.A. Lear, A. Wielgosz, M. Sharma, P. Poirier, G. Stotts, S.E. Black, S. Strother, and M.D. Noseworthy. 2015. Early cerebral small vessel disease and brain volume, cognition, and gait. Annals of Neurology 77 (2): 251-261. 
9. Consortium, German National Cohort. 2014. The German National Cohort: aims, study design and organization. European Journal of Epidemiology. 29 (5): 371.

10. Bos, D., M.M. Poels, H.H. Adams, S. Akoudad, L.G. Cremers, H.I. Zonneveld, Y.Y. Hoogendam, B.F. Verhaaren, V.J. Verlinden, J.G. Verbruggen, and A. Peymani. 2016. Prevalence, clinical management, and natural course of incidental findings on brain MR images: the population-based Rotterdam Scan Study. Radiology 281 (2): 507-515.

11. Borra, R.J., and A.G. Sorensen. 2011. Incidental findings in brain MRI research: what do we owe our subjects? Journal of the American College of Radiology 8 (12): 848-852.

12. Booth, T.C., A. Jackson, J.M. Wardlaw, S.A. Taylor, and A.D. Waldman. 2010. Incidental findings found in "healthy" volunteers during imaging performed for research: current legal and ethical implications. The British Journal of Radiology 83 (990): 456-465.

13. Flores, J., Baruca, A. and Saldivar, R., 2014. Is Neuromarketing Ethical? Consumers Say Yes. Consumers Say No. Journal of Legal, Ethical and Regulatory Issues, $17(2)$.

14. Roth, J., R.F. Keating, J.S. Myseros, A.L. Yaun, S.N. Magge, and S. Constantini. 2012. Pediatric incidental brain tumors: a growing treatment dilemma. Journal of Neurosurgery: Pediatrics 10 (3): 168-174.

15. Health, National, and Medical Research Council. 2018. National Statement on the Ethical Conduct in Human Research. Australia: Canberra.

16. Scanlon, T.M. 1980. What We Owe to Each Other. Cambridge: Harvard University Press.

17. Singer, P., 1972. Famine, affluence, and morality. Philosophy \& Public Affairs, pp.229-243, at 231.

18. Miller, F.G., M.M. Mello, and S. Joffe. 2008. Incidental findings in human subjects research: what do investigators owe research participants? The Journal of Law, Medicine \& Ethics 36 (2): 271-279.

19. Schaefer, G.O., and J. Savulescu. 2018. The right to know: a revised standard for reporting incidental findings. Hastings Center Report 48 (2): 22-32.

20. Beauchamp, T.L., and J.F. Childress. 2001. Principles of Biomedical Ethics. USA: Oxford University Press.

21. Presidential Commission for the Study of Bioethical Issues. Anticipate and Communicate: Ethical Management of Incidental and Secondary Findings in the Clinical, Research, and Direct-to-Consumer Contexts. (December 2013 Report of the Presidential Commission for the Study of Bioethical Issues). Washington, DC: Presidential Commission for the Study of Bioethical Issues; 2013. http://bioethics.gov/sites/default/files/FINALAnticipate Communicate_PCSBI_0.pdf. Accessed 3 July 2020.

22. Weiner, C. 2014. Anticipate and communicate: Ethical management of incidental and secondary findings in the clinical, research, and direct-to-consumer contexts (December 2013 report of the Presidential Commission for the Study of Bioethical Issues). American Journal of Epidemiology 180 (6): 562-564

23. Illes, J., Rosen, A. C., Huang, L., Goldstein, R. A., Raffin, T. A., Swan, G., \& Atlas, S. W. (2004). Ethical consideration of incidental findings on adult brain MRI in research. Neurology, 62(6), pp.888-890. Illes J, Racine E. Imaging or imagining? A neuroethics challenge informed by genetics (2005). The American Journal of Bioethics. 1;5(2): pp.5-18.

24. Fisher, C.E., L. Chin, and R. Klitzman. 2010. Defining neuromarketing: Practices and professional challenges. Harvard Review of Psychiatry 18 (4): 230-237.

25. Murphy, E.R., J. Illes, and P.B. Reiner. 2008. Neuroethics of neuromarketing. Journal of Consumer Behaviour: An International Research Review 7 (4-5): 293-302.

26. Wertheimer, A. 2013. Is payment a benefit? Bioethics 27 (2): 105-116.

27. Wenner, D.M. 2018. The social value requirement in research: from the transactional to the basic structure model of stakeholder obligations. Hastings Center Report 48 (6): 25-32.

28. Knoppers, B.M., Y. Joly, J. Simard, and F. Durocher. 2006. The emergence of an ethical duty to disclose genetic research results: international perspectives. European Journal of Human Genetics 14 (11): 1170-1178.

29. Hegedüs, P., O. von Stackelberg, C. Neumann, S. Selder, N. Werner, P. Erdmann, A. Granitza, H. Völzke, F. Bamberg, R. Kaaks, and R.C. Bertheau. 2019. How to report incidental findings from population whole-body MRI: view of participants of the German National Cohort. European radiology 29 (11): 5873-5878.

30. Wellcome Trust. 2012. Available at: https://wellcome.ac. uk/sites/default/files/wtvm055196_0.pdf. Medical Research Council, Opinion Leader. Assessing public attitudes to health related findings in research. .

31. Kirschen, M.P., A. Jaworska, and J. Illes. 2006. Subjects' expectations in neuroimaging research. Journal of Magnetic Resonance Imaging: An Official Journal of the International Society for Magnetic Resonance in Medicine 23 (2): 205209.

32. Ross, K., 2005. When volunteers are not healthy: Dealing with incidental findings in basic research challenges researchers and study participants alike. EMBO reports, 6(12), pp.1116-1119, at 1118 .

33. Royal, J.M., and B.S. Peterson. 2008. 'The Risks and Benefits of Searching for Incidental Findings in MRI Research Scans', The Journal of Law. Medicine \& Ethics 36 (2): 305-314.

34. Mair, R.W., Benner, T., Fischl, B., Hemphill, B., Hollinshead, M., van der Kouwe, A.J. and Buckner, R.L., 2011. Quantitative reliability for extremely rapid structural data acquisition across time, scanners, and software upgrade. In Proc ISMRM (Vol. 19, p. 2356).

35. Richardson, H.S., and L. Belsky. 2004. The ancillary-care responsibilities of medical researchers: An ethical framework for thinking about the clinical care that researchers owe their subjects. Hastings Center Report 34 (1): 25-33.

36. Illes, J., M.P. Kirschen, K. Karetsky, M. Kelly, A. Saha, J.E. Desmond, T.A. Raffin, G.H. Glover, and S.W. Atlas. 2004. Discovery and disclosure of incidental findings in neuroimaging research. Journal of Magnetic Resonance Imaging: An Official Journal of the International Society for Magnetic Resonance in Medicine 20 (5): 743-747.

37. Milstein, A.C. 2008. Research Malpractice and the Issue of Incidental Findings. Journal of Law, Medicine \& Ethics 36 (2).

38. Senate Community Affairs References Committee. Availability and accessibility of diagnostic imaging 
equipment around Australia. 2018. Commonwealth of Australia. Canberra.

39. Cloft, H.J., T.A. Tomsick, D.F. Kallmes, J.H. Goldstein, and J.J. Connors. 2002. Assessment of the interventional neuroradiology workforce in the United States: a review of the existing data. American Journal of Neuroradiology 23 (10): 1700-1705.

40. Cramer, S.C., J. Wu, J.A. Hanson, S. Nouri, D. Karnani, T.M. Chuang, and V. Le. 2011. A system for addressing incidental findings in neuroimaging research. Neuroimage 55 (3): 1020-1023.

41. The Nuremberg Code. JAMA1996; 276

42. US Department of Health and Human Services, 2013. National commission for the protection of human subjects of biomedical and behavioral research.(1979). The Belmont Report: Ethical principles and guidelines for the protection of human subjects of research, 45.

43. Appelbaum, P.S., L.H. Roth, C.W. Lidz, P. Benson, and W. Winslade. 1987. False hopes and best data: consent to research and the therapeutic misconception. The Hastings Center Report 17 (2): 20-24.

44. Falk, E.B., E.T. Berkman, T. Mann, B. Harrison, and M.D. Lieberman. 2010. Predicting persuasion-induced behavior change from the brain. Journal of Neuroscience 30 (25): 8421-8424.

45. Lindstrom, M., You Love Your iPhone. Literally. New York Times (30 September 2011). https://www.nytimes.com/2011 /10/01/opinion/you-love-youriphone-literally.html. Accessed 12 Apr 2021.

46. Letter to the Editor. The iPhone and the Brain. New York Times (4 October 2011). https://www.nytimes.com/2011/10 /05/opinion/the-iphone-and-thebrain.html. Accessed $12 \mathrm{Apr}$ 2021.

47. Bunnik, E.M., L. Van Bodegom, W. Pinxten, I.D. De Beaufort, and M.W. Vernooij. 2017. Ethical framework for the detection, management and communication of incidental findings in imaging studies, building on an interview study of researchers' practices and perspectives. BMC Medical Ethics 18 (1): 10.

Publisher's Note Springer Nature remains neutral with regard to jurisdictional claims in published maps and institutional affiliations. 